УДК 81.272

\title{
В.А. Кожемякина
}

\section{ЯЗЫКОВАЯ СИТУАЦИЯ И ЯЗЫКОВАЯ ПОЛИТИКА В КАНАДСКОЙ ПРОВИНЦИИ КВЕБЕК}

В статье представлен анализ языковой ситуации и языковой политики в канадской провинции Квебек. Проанализированы федеральные и провинциальные законы о языке, принятые во второй половине ХХ в. и обозначена ситуация, в которой находился французский язык в провинции Квебек. Шестидесятые годы прошлого столетия в Квебеке, которые принято называть «Тихой революцией», был период глубоких социально-политических перемен. Тихая революция носила мирный, эволюционный характер, но в ней участвовало все население провинции. «Революция» сопровождалась изменением этнического дисбаланса в обществе, при котором как политическая, так и экономическая власть находилась в руках англоязычного меньшинства. Другим важным аспектом была модернизация и секуляризация франкоканадской общины и подъём её уровня жизни до среднего уровня англоканадцев. Франкоквебекцы, находившиеся на более низкой ступени экономического развития, оказались на грани потери своего родного языка, что вызвало мощный подъем националистического движения в Квебеке, которое было направлено властями провинции на спасение квебекского варианта французского языка и на улучшение социально-экономической ситуации франкоквебекского сообщества.

Ключевые слова: социолингвистика, языковая политика, языковое законодательство, многонациональные страны, социальные функции языка, языковая ситуация, функционирование языков в коммуникативных сферах.

DOI: $10.35634 / 2412-9534-2020-30-6-993-1000$

Квебек всегда занимал особое место среди субъектов федеративной Канады, не только потому, что эта провинция является самой большой в стране по площади и второй по количеству населения, но главная ее особенность в том, что она всегда была и остается центром канадской франкофонии. Наибольшее количество франкоканадцев проживает в провинции Квебек. По переписи 2016 г. франкофоны в Квебеке составляют 78 \% всего населения, а англофоны - 8,1 \% [16]. Французский язык, будучи родным языком подавляющего большинства населения, играет особую роль в Квебеке, поскольку со второй половины предыдущего века он является единственным официальным языком данной провинции двуязычной Канады. Несомненно, тот факт, что франкофоны являются языковым меньшинством в Канаде, но большинством в провинции Квебек, также играет ключевую роль в развитии этого сообщества и в его языковой политике.

Уникальность языковой ситуации провинции Квебек объясняется сложной историей колонизации Нового Света. В течение двух веков Франция и Великобритания осваивали новые земли и вели друг с другом кровопролитные войны, захватывая чужие колонии.

Христофор Колумб приплыл к берегам Америки в 1492 г., но новая северная территория не заинтересовала Испанию. Вслед за испанскими и португальскими путешественниками на берега американского континента высадились французские исследователи и переселенцы из Франции. Первая французская экспедиция в Новый Свет была организована в 1534 г. под руководством капитана Жака Картье. В 1608 г. организовано первое поселение французов - основан город Квебек, в это время поселение англичан уже год существовало в Виржинии. [1. С. 9-10]. Колонизация французами территории современной Канады с самого начала сопровождалась жестоким англо-французским соперничеством. В течение двух веков Франция и Англия тратили свои силы, энергию и средства как на освоение новых земель, так и на борьбу за право владения ими. Дружественно относящихся индейцев европейцы использовали в своих целях, в случае враждебного отношения или сопротивления их уничтожали. Также европейские поселенцы разжигали междоусобные войны между индейскими племенами, которые велись уже с применением огнестрельного оружия [2. С. 30-31]. Англичане и французы вели долгую и изнурительную войну за права на земли Нового Света, но ни те, ни другие не признавали прав индейцев на их исконные территории. Постоянные военные конфликты за сферы влияния приводили к тому, что многие колонии, как, например, Порт-Руаяль и Квебек переходили несколько раз под юрисдикцию то Франции, то Англии. Соперничество этих двух европейских стран за владения землями и колониями в Северной Америке было особенно интенсивным в трех регионах: 1) в Акадии, привлекавшей оба государства своими океанскими портами; 2) на берегах реки Святого 
Лаврентия и Великих озер, которые являлись прекрасным водным путем в глубь континента; 3) на берегах Гудзонова залива и залива Джеймса [7. С. 77-86].

Не следует забывать, что успех военных столкновений в Новом Свете непосредственно зависел от тех войн, которые вели европейские колониальные державы на территории Европы. Так в 1713 г. в результате долгих военных действий на европейском континенте был подписан Утрехтский мир, по условиям которого Франция вынуждена была уступить Англии Гудзонов залив, Ньюфаундленд и Акадию. Франция сохранила в своем владении острова Сен-Жан (в настоящее время - остров принца Эдуарда) и Королевский (ныне - Кап-Бретон), также французы сохранили за собой право рыбной ловли у берегов Ньюфаундленда. Территория Акадии (современный Новый Брансуик) отходила англичанам и, по условиям договора, её жителям разрешалось покинуть Акадию. Решающее значение для судьбы заморских французских колоний имела Семилетняя война, ставшая заключительным этапом противостояния Англии и Франции в Северной Америке, которое закончилось в 1763 г. [7. С. 129]. В результате изнурительных военных действий в 1758 г. капитулировал город Квебек и в 1760 г. Монреаль. В 1763 г. по условиям Парижского мирного договора Франция была вынуждена отказаться от всех притязаний на Канаду, Новую Шотландию и все острова залива Святого Лаврентия. Франции остались только острова Карибского бассейна: Мартиника и Гваделупа. Вместе с Канадой она уступила Англии долину Огайо и всю свою территорию к востоку от Миссисипи, за исключением Нового Орлеана. Также Франция отдала Испании Луизиану, к западу от Миссисипи. Америка, говорившая до этого, в основном, на французском языке, превратилась в англоязычную территорию. Остался только франкоязычный Квебек, который вошел составной частью в британский доминион Канада.

По Конституции 1867 г. в Канаде официально признано наличие двух государственных языков английского и французского, а закон федерального правительства страны от 1988 г. об официальных языках подтвердил их равный статус [17. С. 13-58]. Тем не менее языковая ситуация в стране такова, что во всех провинциях и территориях ${ }^{1}$ страны, кроме Квебека, функционирует только английский язык. По переписи населения Канады 2016 г. англоканадцы составляют большинство жителей страны $57 \%$, французский язык является родным языком для $21 \%$ населения [16]. В Квебеке, единственной франкоязычной провинции, франкоканадцы составляют подавляющее большинство. Хотя новая Конституция Канады 1982 г. подтвердила наличие двуязычия в стране, тем не менее, основная масса населения владеет только английским языком. Канадцы французского происхождения вынуждены учить английский язык, тогда как для англофонов, проживающих во всех провинциях, кроме Квебека, знание французского не является необходимостью. Многие проблемы и языковые конфликты, возникающие в Канаде и в частности в Квебеке, происходят именно из-за того, что две основные группы населения франкофоны и англофоны - составляют одновременно или большинство, или меньшинство населения в зависимости от места их проживания.

На протяжении столетия франкоканадцы стояли в стране на более низкой ступени экономического и культурного развития и поэтому они постоянно боролись за улучшение своего экономического положения, за сохранение культурного наследия, своих романских корней, пытались отстоять свои права на особое развитие франкоговорящего сообщества в рамках федеративного государства. Но, поскольку политическая и экономическая власть в провинции находилась в руках англоканадцев, положение франкоквебекцев ухудшалось, ситуация в Квебеке осложнялась тем, что в провинции царил ярко выраженный католический клерикализм, тормозящий политическое и экономическое развитие общества. В этой ситуации французский язык постепенно заменялся просторечным говором, прозванным жуаль. Жуаль - это социолект в квебекском языке, говор народных низов, он сформировался в процессе общения франкоговорящих рабочих с мастерами-англичанами в Монреале в конце XIX - начале XX вв. Жуаль обеспечивал неформальное, семейное и дружеское общение, а также коммуникацию на низшем уровне в производственной сфере, его название происходит от особенного квебекского произнесения слова cheval 'лошадь', слова часто употреблявшегося в Монреале, где лошадей использовали для извоза [3]. В возникновении и формировании жуаля сыграли роль разные факторы: во-первых, интенсивная иммиграция англичан во франкоязычный Монреаль, предпринятая британским правительством во второй половине XIX в. для быстрейшей ассимиляции франкоканадцев, а, во-вторых, увеличившийся приток малообразованных крестьян в города в связи с поисками работы. В этот период сельское франкоязычное население провинции интенсивно мигрирует в города, где в силу своего низкого социального

\footnotetext{
${ }^{1}$ Канада состоит из десяти провинций и трех территорий.
} 
статуса и отсутствия полноценного образования вынуждено идти работать на заводы, где бывшие крестьяне занимались тяжелым, малоквалифицированным трудом. А во-вторых, формирование жуаля было вызвано тем, что франкоквебекцы находились в постоянной изоляции, в окружении англоязычного населения, занимавшего доминирующее положение в обществе, что неизбежно оказывало влияние на качество французского языка и его смешение с английским языком. Отличительной чертой жуаля было присутствие в нем большого количества англицизмов. Недаром его называли «franglais», то есть смесь французского и английского языков. Жуаль определил целую эпоху в развитии квебекского варианта французского языка и явился детонатором для начала борьбы франкоквебекцев за качество и чистоту своего родного языка и его приоритетное функционирование во всех сферах общения во франкоязычной провинции Канады, поскольку распространение жуаля могло грозить квебекскому франкоговорящему обществу потерей их родного языка [8. С. 325-328].

Шестидесятые годы прошлого столетия в Квебеке принято называть «тихой революцией», это был период глубоких социально-политических перемен. Тихая революция носила мирный, эволюционный характер, но в ней участвовало все население провинции. «Революция» сопровождалась изменением этнического дисбаланса в обществе, при котором как политическая, так и экономическая власть находилась в руках англоязычного меньшинства. Другим важным аспектом была модернизация и секуляризация франкоканадской общины и подъём её уровня жизни до среднего уровня жизни англоканадцев.

Преобразования в Квебеке затронули сферы политической, экономической, социальной, культурной и языковой жизни общества. Начиная с 1960 г. Квебек перешел от клерикального консерватизма и социокультурного иммобилизма к переменам, мобилизации, переоценке политической ориентации в соответствии с экономическими интересами квебекского общества. Эти изменения не были революционными сами по себе, но они позволили Квебеку преодолеть отставание и встать в один ряд с промышленно развитыми провинциями страны. Начавшийся в 1960-е гг. прошлого столетия, процесс франсизации квебекского общества кардинально изменил всю жизнь Квебека уже к началу этого века.

Французский язык стал для франкофонов Квебека как оружием борьбы, так и символом освобождения от статуса отчужденной части общества. Это новое видение языка породило серию законов о языке: закон 63 (Закон об обязательном обучении во французских школах для детей иммигрантов в Квебеке, 1969 г.) [10], Закон 22 (Закон об официальных языках провинции Квебек, 1974 г.) [11] и Закон 101 (Хартия французского языка, 1977 г.) [17. С. 157-219], благодаря которому французский язык окончательно перешел из статуса родного языка франкоквебекцев в статус единственного официального языка провинции, что стало кульминацией длительного процесса национального самоутверждения франкофонов.

В борьбе за перемены во франкоязычной Канаде можно отметить три основных направления: первое - за экономическую и культурную автономию Квебека в составе конфедерации; второе - за полную независимость Квебека и выход из конфедерации, третье направление придерживается идеи возможности осуществления биэтнического, бикультурного, бинационального англо-франкоканадского единства в рамках неофедерализма [2. С. 56].

В 1960 г. к власти в Квебеке пришла Либеральная партия, которая приступила к реализации своей программы под названием «Время перемен». Премьер-министр и глава Либеральной партии Жан Лесаж получил прозвище «отец Тихой революции», т. к. хотел преобразовать институты и менталитет квебекского общества с помощью разработанной программы, выходя далеко за рамки простых экономических реформ. Начавшаяся «Тихая революция» ознаменовала период кардинальных изменений в обществе, характеризующийся переменами в политическом руководстве, трансформацией социально-экономической системы, возвращением французского языка во все коммуникативные сферы и утверждением квебекской идентичности.

Менее чем за тридцать лет провинция Квебек была преобразована, модернизирована и совершила значительный рывок в своем развитии. Квебеку пришлось за несколько десятилетий наверстать отставание от индустриально развитых канадских провинций и других стран, восстановить контроль над своим природным богатством и сформировать франкоязычную квебекскую элиту, которая могла бы управлять провинцией и способствовать ее процветанию. С точки зрения укрепления позиций французского языка, первым конкретным шагом, предпринятым для его продвижения, является создание в 1961 г. Квебекского управления французского языка (Office québécois de la langue française). Следует отметить большую помощь, оказанную федеральными властями Квебеку. Столкнувшись с 
ростом квебекского национализма и осознавая важность французского языка для народа Квебека, федеральное правительство создало в 1963 г. Королевскую комиссию по двуязычию и бикультурализму (Commission royale d'enquête sur le bilinguisme et le biculturalisme). В 1968 г. Правительство Квебека сформироало Комиссию по изучению языковой ситуации, которая должна была помочь разработать необходимую языковую политику. Проведя анализ языковой и экономической ситуации в Квебеке, эти две комиссии подтвердили документально экономическое неравенство франкофонов и англофонов в стране, а также неравенство французского и английского языков в Квебеке и Канаде, что вызвало необходимость принятия законов о языках, направленных на укрепление позиций французского языка во франкоязычной провинции и в стране [5].

В 1969 г. федеральное правительство приняло Закон об официальных языках Канады, который закрепил равенство французского и английского языков в институтах федеральной власти и были объявлены двуязычные округа, в которых должны соблюдаться языковые права французских и английских меньшинств [12]. В том же году правительство Квебека приняло закон 63 [10]. В 1974 г. был принят важный закон 22, который объявил французский единственным официальным языком в Квебеке: «Принимая во внимание то, что французский язык является национальным достоянием, которое государство обязано сохранять, и тот факт, что правительство Квебека обязано приложить все усилия для обеспечения его приоритета и содействовать его сохранению и развитию (...) Ее Величество по совету и с согласия Национального собрания Квебека приказывает следующее: Французский язык является официальным языком Квебека²» [11]. Победа Квебекской партии на выборах 1976 г. ознаменовала решающий поворотный момент в языковой политике провинции. Продолжая реформы, начатые в период Тихой революции, правительство Рене Левека проводило политику интервенционистского государства, применяя ее и в области функционирования языка. Хартия французского языка, часто более известная под неофициальным названием Закон 101, была принята в 1977 г., через год после прихода к власти Квебекской партии. Франкоканадцы назвали принятие этого закона историческим событием, которое полностью изменило соотношение между английским и французским языками. Языковая стратегия Хартии французского языка была основана на трех общих принципах, направленных на решение языковых проблем квебекского общества:

а) остановить процесс ассимиляции и минимизации числа франкоязычных жителей;

б) обеспечить улучшение уровня социально-экономического положения франкоязычного большинства;

в) реализовать приоритет французского языка в Квебеке [17. С. 157-219].

Учитывая, тот факт, что в то время население Квебека состояло из 80,8 \% франкофонов, 14,7 \% англоязычных жителей и 4,5\% аллофонов (то есть иммигрантов, говорящих на других языках, кроме английского или французского), было важно, чтобы французский, а не английский, стал общим языком всех квебекцев. Следовательно, так важен был отказ от официального двуязычия, который, как показали предыдущие годы, являлся самой большой угрозой для жизнеспособности французского языка, поскольку он приводил к деградации языка большинства и способствовал монолингвизму англофонов.

Этот закон, который подтверждал, что французский язык является единственным официальным языком Квебека, давал, наконец, возможность укрепить его позиции в провинции. Например, чтобы ограничить англицизацию аллофонов и самих франкофонов, закон позволяет поступать в англоязычные школы только тем детям, чьи родители или братья и сестры посещали английскую школу в Квебеке. Все остальные дети обязаны были учиться в школах с французским языком обучения. Программа франсизации обозначила две коммуникативные сферы в качестве основных - сфера образования и сфера производства. Правительство ввело программу франсизации на всех предприятиях, чтобы обеспечить функционирование французского языка как рабочего на производстве. Еще в 60-е гг. ХХ в. Королевская Комиссия по билингвизму и бикультурализму, исследовав языковую ситуацию в стране и, особенно, в Квебеке, констатировала, что предприятия в этой франкоязычной провинции принадлежали в основном или англоканадцам, или иностранцам. В работах Комиссии, как и в других исследованиях, подтверждалось, что французский язык не являлся рабочим языком большинства квебекских трудящихся, хотя бо́льшую их часть составляли франкоканадцы [5]. Еще в 1974 г. в Законе о языках (закон 22) была указана необходимость введения французского языка в трудовую деятельность квебекцев. Но закон только инициировал эту необходимость, но не предусматривал никаких обязательств

\footnotetext{
${ }^{2}$ Перевод текстов законов и цитат в статье сделан автором статьи.
} 
и мер принуждения по отношению к предприятиям. Хартия французского языка положила начало процессу возвращения французскому языку всей функциональной мощности, которую он должен иметь во франкоязычном обществе. Статьи 135 - 156 Хартии [17. С. 197-204] законодательно определяют сложный процесс франсизации сферы производства. Программа касалась всех предприятий, которые были обязаны создать свой комитет по франсизации, обязанный организовывать и координировать перевод рабочего процесса на данном предприятии на французский язык. Комитет должен был представлять отчет в Квебекское управление французского языка, которое в свою очередь разрабатывало программу по переводу на французский язык работы данного предприятия, исходя из описанного состояния функционирования на нем языков. Предприятие обязано было исполнять все пункты своей программы и проводить процесс франсизации по предусмотренным этапам.

В 2014 г. было опубликовано исследование П. Белана о функционировании французского языка как рабочего языка в Квебеке, основанное на переписи населения Канады 2011 г. [15]. Так к 2011 г. $82 \%$ трудящихся частного сектора использовали чаще всего французский язык на рабочем месте, $6 \%$ французский и английский и $12 \%$ - чаще говорили на рабочем месте на английском языке. В государственном секторе французский язык употреблялся чаще: 88 \% трудящихся пользовались французским языком, $3 \%$ - двумя языками и $9 \%$ чаще всего - английским. В государственных учреждениях $95 \%$ служащих изъяснялись на французском языке, в области медицины пользовались французским - 88 \%, а в системе образования $-82 \%$ [4].

По данным переписей населения 2006 г. и 2016 г. регулярное использование французского языка на рабочем месте за этот период оставалось довольно стабильным - 94,4 \% . Что касается английского языка, то, хотя 42,5\% работников в Квебеке использовали этот язык на работе в 2016 г. (по сравнению с 40,4 \% в 2006 г.), его преимущественное использование в качестве рабочего языка изменилось с 12,4 \% в 2006 г. до 12,0\% в 2016 г. Снижение преимущественного использования французского языка на работе, как и английского, привело к увеличению доли работников, которые использовали французский язык наравне с английским. Так, в 2016 г. 7,2 \% рабочих Квебека сообщили, что они в равной степени используют английский и французский языки по сравнению с 4,6 \% в 2006 г. [14; 16].

Хартия французского языка законодательно подтвердила, что франкоговорящие квебекцы, являясь большинством квебекского общества, могут использовать предоставляемые им политические полномочия. Следует отметить, что подобный закон, принятый провинцией федеративного государства, является уникальным событием в мире.

Если рассматривать языковую политику Квебека, то стоит остановиться на шести основных принципах языкового обустройства в провинции:

1. Квебекское общество не может быть двуязычным. Официальный билингвизм не может устраивать квебекское общество, т. к. французский язык, как более слабый функционально, не может быть поставлен в равные условия с более сильным в этом смысле английским языком. Именно эта ситуация и привела к признанию только одного официального языка провинции Квебек - французского.

2. Именно все учреждения и предприятия, а не отдельные индивиды, определяют имеющуюся языковую ситуацию и только они могут, в случае необходимости, её изменить. На каждом предприятии и учреждении лежит ответственность за соблюдением статуса и норм литературного французского языка во внутреннем общении и внешних контактах.

3. Афиши и коммерческая реклама отражают статус и нормированность языка в квебекском обществе и тот факт, на каком языке они составлены, имеет чрезвычайную важность для граждан провинции. Значимость использования французского языка в рекламе и вызвала тот пункт Хартии французского языка, где языком афиш и рекламы является только французский язык.

4. Защита прав потребителя требует, чтобы вся информация о продуктах и документы, сопровождающие эти продукты, были составлены на родном языке потребителей, что и потребовало внести в Хартию пункт об использовании французского языка во всех подобных текстах.

5. В демократическом обществе, каким является Квебек, культурно-этнические меньшинства имеют право поддерживать знание своих языков и свою культурную деятельность. Поэтому закон разрешает использование всех языков в культурной сфере (средства массовой коммуникации, ассоциации, торговля специфическими продуктами питания и одежды, религиозные учреждения и т. п.).

6. Деятельность по нормированию терминологии должна проводиться лингвистами в сотрудничестве со специалистами данных областей: техниками, инженерами, профессорами и т. д. 
7. Все контакты вне территории провинции часто требуют использование не французского, а других языков, чаще всего, английского, особенно в Северной Америке. Языковые законы уточняют, что для таких контактов, возможно употребление других языков [6. С. 1-12].

В 70-е и 80-е гг. прошлого столетия, во время активного проведения программы франсизации, многие англоквебекцы покинули Монреаль. Уехавшие англофоны составили две трети жителей провинции, покинувших Квебек. Прибывшие за это время иммигранты были вынуждены учить французский язык и строить свою рабочую и общественную жизнь при помощи французского языка. Англофоны, проживающие в настоящее время в Квебеке, вынуждены учить французский язык и, надо отметить, что число билингвов среди них значительно увеличилось. Если в 1971 г. насчитывалось только $33 \%$ англофонов-билингвов в Квебеке, то в настоящее время этот показатель доходит до $70 \%$ [16], что свидетельствует о признании французского языка основным языком официального и неофициального общения в Квебеке.

Некоторые статьи Хартии французского языка были оспорены в Верховном суде Канады. В исках утверждалось, что они нарушают индивидуальные свободы, гарантированные Канадской хартией прав и свобод, и что они не соответствуют Канадской Конституции как, например, статья 73 об обязательности получения образования на французском языке, поскольку статья 23 Канадской Хартии прав и свобод устанавливает, что это право «осуществляется в любой провинции, где число детей языкового меньшинства является достаточным для организации в этой местности обучения на языке меньшинства, обеспечиваемого общественным фондом» [9]. Верховный суд Канады в 1984 г. лишил законной силы статью 73 Хартии французского языка. Правительство Квебека было вынуждено заменить эту статью другой, которая позволяла теперь учиться в начальной и средней школе на английском языке тем детям, чьи родители, братья или сестры получили образование на английском языке в Канаде, а не только в Квебеке.

Отстаивая свою Хартию французского языка, власти Квебека ссылались на статью 1 Канадской хартии прав и свобод, в которой говорится: «Канадская хартия прав и свобод гарантирует все права и свободы, которые в ней изложены. Они могут быть ограничены только правовыми нормами, которые юридически разумно обоснованы в границах, существующих в свободном демократическом обществе» [9]. Представители Квебека считали, что статья 73 Хартии французского языка как раз и является таким «разумным» ограничением в рамках свободного и демократического общества. После принятия Канадской Хартии прав и свобод, она была включена в Конституцию Канады, 52 статья которой утверждает ее высшим законом Канады, после чего она делает недействительными несовместимые с ней положения любого другого правового акта. Впоследствии все канадские провинции подписали договор о принятии новой Конституции, за исключением Квебека [13. С. 98-99].

Все общество было охвачено организацией преобразования на всех уровнях; были созданы учреждения здравоохранения во всех крупных центрах; количество государственных компаний значительно увеличилось, и все основные государственные услуги (полиция, дороги, энергетика, местное самоуправление) предоставлялись во всех уголках территории провинции. Будучи составной частью федеративного государства, Квебек стал провинцией с единственным официальным французским языком, что обозначило новой этап культурной революции, которая осуществила заметные преобразования в политико-экономической сфере, в сферах управления, бизнеса и промышленности, которые до сих пор были традиционно англоязычными и были недоступны для франкоговорящих квебекцев. Кроме того, развивая функционирование своего родного языка, Квебек тем самым способствовал укреплению официально признанного двуязычия в федеративном государстве.

Одной из основных задач процесса франсизации было использование нормированного литературного французского языка и, в частности, наличие хорошо разработанных систем специальной терминологии. С тех пор, как квебекское правительство объявило о насущной необходимости сделать французский язык рабочим языком Квебека, большое внимание было уделено выработке и закреплению норм квебекского французского языка и разработке словарей разных специальностей.

Квебекские ученые-лингвисты, разрабатывавшие языковую политику провинции по возрождению французского языка, составлявшие программы франсизации для всех сфер коммуникации, в последние десятилетия занимаются разработкой норм и правил квебекского варианта французского языка, анализом его особенностей, совершенствованием его терминологических систем.

В заключение можно сказать, что франкоквебекцы организовали свой собственный путь развития благодаря широкомасштабной языковой политике, проводимой как властями провинции, так и 
всем квебекском обществом. Языковая политика Квебека опиралась на большое количество законов о языке, которые определили основные пути осуществления этой политики. Благодаря совместным усилиям всего франкоквекского сообщества французский язык не только стал единственным официальным языком Квебека, но успешно выполняет все функции официального языка провинции. Победа франкоквебекцев, одержанная в борьбе за возрождение своего родного языка, была осуществима в условиях демократического многонационального государства Канады, где сами народы могут выбирать свой собственный путь развития и, ощущая себя представителями единой канадской нации, могут сохранять свою языковую и культурную идентичность. При этом можно отметить, что в процессе этнической идентификации франкоквебекцев французский язык перешел из фактора лингвокультурной идентичности в фактор территориальной идентичности. Власти Квебека обратились к федеральным властям страны с предложением признать наличие новой нации квебекцев в составе единой Канады и Парламент Канады признал большинством голосов в 2006 г. существование в стране новой нации. Таким образом, мы видим, что в результате конфликтного противостояния франкоканадцев и англоканадцев французский язык из маркера этнокультурной идентификации франкоквебекцев стал обязательным маркером для всего сообщества жителей провинции Квебек.

\section{СПИСОК ЛИТЕРАТУРЫ}

1. Клоков В.Т. Французский язык в Северной Америке. Саратов: Изд-во Саратовского университета, 2005. 399 с.

2. Реферовская Е.А. Французский язык в Канаде. Л.: Наука, 1972. 216 с.

3. Aménagement linguistique dans le monde. Le joual au Québec. URL: http://www.axl.cefan.ulaval.ca/francophonie/ Quebec-lex-joual.htm

4. Béland P. L'usage des langues au travail dans le secteur public au Québec en 2011. Un portrait statistique. Québec: Conseil supérieur de la langue française, 2014. 59 p.

5. Commission royale d'enquête sur le bilinguisme et le biculturalisme. URL: http://www.thecanadianencyclopedia.ca/ fr/article/royal-commission-on-bilingualism-and-biculturalism/

6. Corbeil J.-Cl. Langues et usage des langues. Quebec: Conseil de la langue francaise, 1986. $154 \mathrm{p}$.

7. Lacroix J.- M. Histoire du Canada. P.: Editions Tallandier, 2016. 480 p.

8. Le français au Québec. 400 ans d'histoire et de vie. Québec: Fides, 2008. 679 p.

9. Loi constitutionnelle de 1982. Charte canadienne des droits et libertés. URL: http://laws-lois.justice.gc.ca/fra/ const/page-15.html (дата обращения: 11.02.2020).

10. Loi pour promouvoir la langue française au Québec. 1969. URL: https://www.oqlf.gouv.qc.ca/ 50ans/images/ Bill_63.pdf

11. Loi sur la langue officielle (loi 22) 1974. URL: http://www.axl.cefan.ulaval.ca/amnord/quebec-loi-1974.htm (дата обращения: 11.02.2020).

12. Loi sur les langues officielles du Canada. 1969. URL: http://www.axl.cefan.ulaval.ca/amnord/cnd-loilanguesofficielles1969.htm

13. Paillé M. La Charte de la langue française et l'école: blan et orientation démographiques // L'Etat de la langue française au Québéc. Bilan et prospective. Québec: Conseil de la langue française, 1986. T. I. P. 67-123.

14. Recensement de la population du Canada de 2006. URL: https://www12.statcan.gc.ca/census-recensement/ 2006/index-fra.cfm

15. Recensements de la population du Canada 2011. URL: https://www12.statcan.gc.ca/census-recensement/2011/ index-fra.cfm

16. Recensement de la population du Canada de 2016. URL: https://www12.statcan.gc.ca/census-recensement/2016/dp$\mathrm{pd} /$ index-fra.cfm

17. Recueil des législations linguistiques dans le monde. T. 1. Le Canada fédéral et les provinces canadiennes. Quebec: Centre International de recherche en aménagement linguistique, 1994. 300 p.

Кожемякина Валентина Алексеевна, кандидат филологических наук, доцент, старший научный сотрудник

Институт языкознания Российской академии наук, Научно-исследовательский центр по национально-языковым отношениям 125009, Россия, г. Москва, Большой Кисловский пер., 1, стр. 1

E-mail: kojemiakina@gmail.com 


\title{
V.A. Kozhemyakina
}

\section{LANGUAGE SITUATION AND LANGUAGE POLICY IN THE CANADIAN PROVINCE OF QUEBEC}

\author{
DOI: $10.35634 / 2412-9534-2020-30-6-993-1000$
}

The article analyzes the language situation and language policy in the Canadian province of Quebec. The Federal and provincial laws on the language adopted in the second half of the XX century are analyzed and the situation in which the French language was in the province of Quebec is indicated. The sixties of the last century in Quebec is called the "quiet revolution", it was a period of profound social and political changes. The quiet revolution was peaceful, evolutionary, but it involved the entire population of the province. The "revolution" was accompanied by a change in the ethnic imbalance in the society, in which the both political and economic powers were in the hands of the English-speaking minority. Another important aspect was the modernization and secularization of the Franco-Canadian community and the rise of its standard of living up to the average level of Anglo-Canadians one. French-speaking Canadians who were at a lower stage of economic development, was on the edge of loosing their native language, which caused a strong rise of the nationalist movement in Quebec, which was directed by provincial authorities to rescue the Quebec version of the French language and improving socio-economic situation of the French speaking community.

Keywords: sociolinguistics, language policy, language legislation, multinational countries, social functions of language, language situation, languages functioning in communication spheres.

\section{REFERENCES}

1. Klokov V.T. Французский язык в Северной Америке Franczuzskij yazyk v Severnoy Anerike [French in North America]. Saratov: Izd-vo Saratovskogo universiteta, 2005. 399 p. (In Russian)

2. Referovskaya E.A. Franczuzskij yazy`k v Kanade [French in Canada] Leningrad: Nauka, 1972. 216 p. (In Russian).

3. Aménagement linguistique dans le monde. Le joual au Québec. URL: http://www.axl.cefan.ulaval.ca/francophonie/ Quebec-lex-joual.htm

4. Béland P. L'usage des langues au travail dans le secteur public au Québec en 2011. Un portrait statistique. Québec: Conseil supérieur de la langue française, 2014. 59 p.

5. Commission royale d'enquête sur le bilinguisme et le biculturalisme. URL: http://www.thecanadianencyclopedia.ca/ fr/article/royal-commission-on-bilingualism-and-biculturalism/

6. Corbeil J.-Cl. Langues et usage des langues. Quebec: Conseil de la langue francaise, 1986. $154 \mathrm{p}$.

7. Lacroix J.- M. Histoire du Canada. P.: Editions Tallandier, 2016. 480 p.

8. Le français au Québec. 400 ans d'histoire et de vie. Québec: Fides, 2008. 679 p.

9. Loi constitutionnelle de 1982. Charte canadienne des droits et libertés. URL: http://laws-lois.justice.gc.ca/fra/ const/page-15.html (дата обращения: 11.02.2020).

10. Loi pour promouvoir la langue française au Québec. 1969. URL: https:/www.oqlf.gouv.qc.ca/ 50ans/images/ Bill_63.pdf

11. Loi sur la langue officielle (loi 22) 1974. URL: http://www.axl.cefan.ulaval.ca/amnord/quebec-loi-1974.htm (дата обращения: 11.02.2020).

12. Loi sur les langues officielles du Canada. 1969. URL: http://www.axl.cefan.ulaval.ca/amnord/cnd-loilanguesofficielles 1969.htm

13. Paillé M. La Charte de la langue française et l'école: blan et orientation démographiques // L'Etat de la langue française au Québéc. Bilan et prospective. Québec: Conseil de la langue française, 1986. T. I. P. 67-123.

14. Recensement de la population du Canada de 2006. URL: https://www12.statcan.gc.ca/census-recensement/ 2006/index-fra.cfm

15. Recensements de la population du Canada 2011. URL: https:/www12.statcan.gc.ca/census-recensement/2011/ index-fra.cfm

16. Recensement de la population du Canada de 2016. URL: https://www12.statcan.gc.ca/census-recensement/2016/dp$\mathrm{pd} /$ index-fra.cfm

17. Recueil des législations linguistiques dans le monde. T. 1. Le Canada fédéral et les provinces canadiennes. Quebec: Centre International de recherche en aménagement linguistique, 1994. 300 p.

Received 20.04.2020

Kozhemyakina V.A., Candidate of Philology, Associate Professor, Senior researcher Institute of Linguistics of the Russian Academy of Sciences, Research Center for Ethnic and Language Relations Bolshoi Kislovsky per., 1/1, Moscow, Russia, 125009

E-mail: kojemiakina@gmail.com 